\title{
Ventilator management recommendations in COVID-19
}

\author{
Oscar Torres-Aguilar* \\ Intensive Care Unit, Andalucía Hospital, Torreon, Coahuila, Mexico
}

In December 2019, a new pandemic surfaced caused by a new virus known as severe acute respiratory syndrome coronavirus 2 and new disease COVID-19, reported at first in Wuhan, China. By April 27, 2019, according to data by the WHO, there were $2,878,196$ confirmed cases worldwide, with the US being the most affected with over 1 million cases alone. In the same period of time, 198,668 deaths have been registered, and over 907,000 have recovered around the world. In Mexico, reports show 15,529 confirmed cases and 1434 deaths.

Coronaviruses are a very diverse group of viruses, of the RNA type. The clinical picture of COVID-19 is characterized by fever, headaches, cough, fatigue, myalgias, diarrhea, vomiting, and laboratory alterations such as lymphopenia, neutrophilia, elevated AST levels, troponin I, bilirubin, reactive protein C, ferritin, and D-dimer. Laboratory studies are linked to the development of an acute respiratory distress syndrome (ARDS). A high fever $\left(39^{\circ} \mathrm{C}\right)$ and the use of methylprednisolone are associated with a lower mortality ${ }^{1}$.

\section{Ventilator management in COVID-19}

Patients with a COVID-19 infection present data of hypoxemic acute respiratory failure, bearing in mind that of the different mechanisms of hypoxemia, the short circuit is the only one that does not respond to high $\mathrm{FiO}_{2}$, and this is the main pathophysiological mechanism of the hypoxemia caused by COVID-19. Next, there is an extensive pulmonary damage, observing pneumocyte desquamation and the formation of hyaline membranes, pulmonary edema, and inflammatory mononuclear interstitial infiltration, mainly lymphocytes, all compatible with ARDS, and thus unresponsive to an oxygen supply. When beginning with high flow (PNAF or puritan) and a persistence of hypoxemia $\left(\mathrm{SpO}_{2}<\right.$ $90 \%$ and $\mathrm{PaO}_{2}<60 \mathrm{mmHg}$ ), orotracheal intubation ought to be taken into consideration over non-invasive mechanical ventilation due to the risk of droplet dispersion. Once intubated, I recommend the following initial parameters for ventilator management among these patients: assist-control volume ventilation (ACV), with tidal volume (TV) of $6 \mathrm{ml} / \mathrm{kg}$ or less predicted body weight ([size in $\mathrm{cm}-152.4$ [0.91] +45.5 in female and +50 in male), positive end-expiratory pressure (PEEP) $10 \mathrm{~cm}$ $\mathrm{H}_{2} \mathrm{O}$, respiratory rate $(R R)$, the closest to the $R R$ before intubation, $\mathrm{FiO}_{2}$ at $100 \%$, and a peak inspiratory flow rate $\left(\mathrm{V}_{\max }\right)$ necessary to maintain an I:E relation of 1:2. I recommend beginning with ACV since it is the only modality that in each breath delivers the predetermined volume, thus avoiding secondary damage from a volume $>6 \mathrm{ml}$. I suggest starting with a PEEP of $10 \mathrm{~cm}$ $\mathrm{H}_{2} \mathrm{O}$ since it allows for better ARDS scrutiny and classification ${ }^{2}$. After setting initial parameters in the ventilator, we ought to take arterial blood gas at $30 \mathrm{~min}$ and classify ARDS with the Berlin criteria ${ }^{3}$. If it is mild $\left(\mathrm{PaO}_{2} /\right.$ $\mathrm{FiO}_{2}<300$ and $>200$ ), leaving PEEP at $8 \mathrm{~cm} \mathrm{H} \mathrm{Cm}_{2} \mathrm{O}$, if moderate $\left(\mathrm{PaO}_{2} / \mathrm{FiO}_{2}<200\right.$ and $\left.>100\right)$ with the PEEP at $12 \mathrm{~cm} \mathrm{H} \mathrm{H}_{2} \mathrm{O}$, and if it is severe $\left(\mathrm{PaO}_{2} / \mathrm{FiO}_{2}<100\right)$ maintain PEEP at $16 \mathrm{~cm} \mathrm{H}_{2} \mathrm{O}^{4}$. We must repeat this after 30 min with $\mathrm{FiO}_{2}$ at $100 \%$. In cases, in which the patients with severe and moderate ARDS, where $\mathrm{PaO}_{2} /$ $\mathrm{FiO}_{2}$ stays at $<150 \mathrm{mmHg}$, the following actions should 


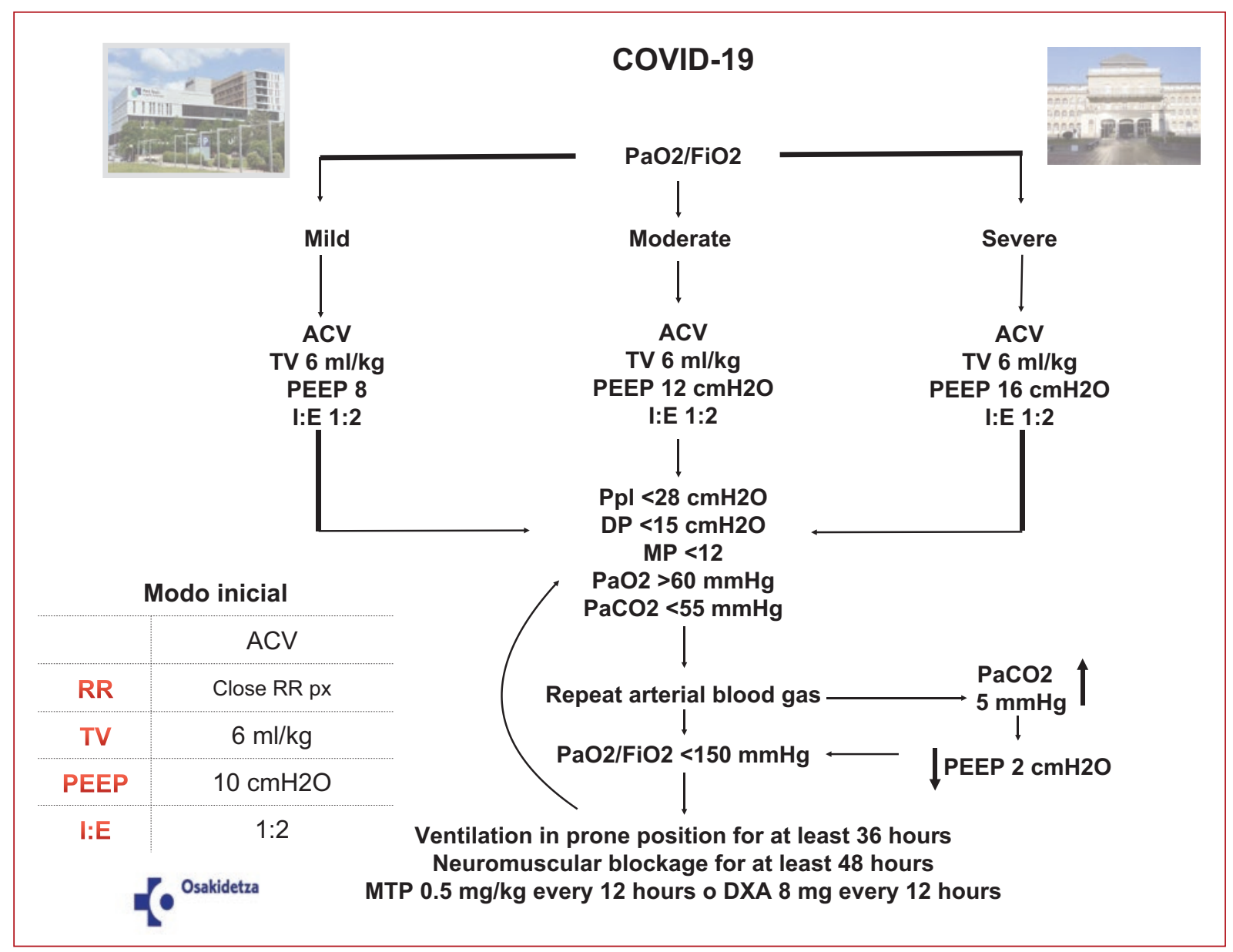

Figure 1. Algorithm 1. ACV: Assist control volume; DP: driving pressure; MP: mechanical power; PEEP: positive end expiratory pressure; Ppl: plateau pressure; RR: respiratory rate; TV: tidal volume.

be performed: place the patient in the prone position ${ }^{5}$ and begin infusion of a muscle relaxant (cisatracurium $50-100 \mathrm{mg}$ in $100 \mathrm{ml}$ of saline solution $0.9 \%$ ) for $24 \mathrm{~h}$ and administer methylprednisolone at $0.5 \mathrm{mg} / \mathrm{kg}$ of predetermined weight every $12 \mathrm{~h}$ at the moment of hospital admission or dexamethasone $8 \mathrm{mg}$ through IV every 12 h. Moreover, these patients, despite the fact that they may have a low or high compliance, may become overdistended with PEEP; hence, we suggest that if $\mathrm{PaCO}_{2}$ increases $5 \mathrm{mmHg}$, subsequent to setting the PEEP at a determined number due to the severity of ARDS despite maintaining RR, TV, and decrease PEEP at 2 $\mathrm{CmH}_{2} \mathrm{O}$ like suggest the algorithm in figure 1 (Fig. 1).

There are other methods for PEEP titration, such as the FiO/PEEP adjustment, better compliance, EXPRESS protocol, and the stress index, which have been evaluated in comparative studies, without finding evidence that one study is better than the other. However, in a study conducted by $\mathrm{me}^{4}$, where we evaluated these same methods of PEEP titration and the use of lung ultrasounds to assess overdistention, we found that a PEEP of 8,12 , and 16, depending on whether the ARDS is mild, moderate, or severe, respectively, correlated well with the overdistended areas and with better compliance. For these reasons, I consider this method to be ideal given the fact that we should limit our exposure time given our adjacent risk of infection to use conventional near-patient PEEP titration techniques.

Other parameters we must monitor, since they also impact survival rate, are plateau pressure $(\mathrm{Ppl})$, under $27 \mathrm{cmH}_{2} \mathrm{O}^{4}, \mathrm{PaO}_{2}>60 \mathrm{mmHg}$, and $\mathrm{PaCO}_{2}<5 \mathrm{mmHg}^{4}$. These three measures are together called "right ventricle-protective ventilation, to avoid acute cor pulmonale. In addition, we must watch for alveolar driving pressure (DP $=$ Ppl-PEEP) under $15 \mathrm{~cm} \mathrm{H}_{2} \mathrm{O}$ and mechanical power under 12, which are obtained using the following formula: $0.098 \times R R \times$ TV (Ppico $-[D P / 2])$. 


\section{PEEP weaning}

There are no articles on when to begin the reduction of PEEP or when patients can be considered for said action. This will depend on dependent and independent variables of mechanical ventilation according to the chosen ventilation modality, observing that the patient in ACV has the same volume tidal (VT) and PEEP as was determined, the Ppeak, Ppl, and DP will reduce, that is, there is alveolar recruitment, and pulmonary compliance will improve. On the other hand, if we use a pressure modality (assist-control pressure, BiLevel, and APRV), we are able to observe the changes in the VT and flow variables, and in this case, with the same Ppeak, Ppl, PEEP, and DP, we can see a gradual increase in flow/VT, even going over the alveolar protection goals ( $>6 \mathrm{ml} / \mathrm{kg}$ predetermined weight). If we observe all this after $12-24 \mathrm{~h}$ of stability and $\mathrm{PaO}_{2} / \mathrm{FiO}_{2}>$ $150 \mathrm{mmHg}$, I suggest the following diagram for PEEP weaning: reduce the patient's $\mathrm{FiO}_{2}$ by $10 \%$, and if the $\mathrm{SpO}_{2}$ does not decrease by $5 \%$, reduce the PEEP by 2 $\mathrm{cm} \mathrm{H}_{2} \mathrm{O}$, and reassess in $8 \mathrm{~h}$. Repeat the same maneuver, reduce $\mathrm{FiO}_{2}$ by $10 \%$ and if the $\mathrm{SpO}_{2}$ stays steady, lower the PEEP $2 \mathrm{~cm} \mathrm{H}_{2} \mathrm{O}$ once again, and so on, every $8 \mathrm{~h}$, until we accomplish at least a PEEP of $10 \mathrm{~cm} \mathrm{H}_{2} \mathrm{O}$, enough to wake our patients up, and at that moment consider spontaneous modalities over-controlled ones.
It will always be preferable that the patient is awake and in spontaneous modalities to avoid VM-related diaphragmatic weakness as much as possible.

\section{Conflicts of interest}

The author declares not to have any conflicts of interest.

\section{Funding}

There is no financing of any kind for this study.

\section{References}

1. Wu C, Chen X, Cai Y, Xia J, Zhou X, Xu S, et al. Risk factors associated with acute respiratory distress syndrome and death in patients with coronavirus disease 2019 pneumonia in Wuhan, China. JAMA Intern Med. 2020. doi:10.1001/jamainternmed.2020.0994.

2. Villar J, Blanco J, del Campo R, Andaluz-Ojeda D, Díaz-Domínguez FJ, Muriel A, et al. Assessment of $\mathrm{PaO}_{2} / \mathrm{FiO}_{2}$ for stratification of patients with moderate and severe acute respiratory distress syndrome. BMJ Open. 2015;5:e006812

3. ARDS Definition Task Force, Ranieri VM, Rubenfeld GD, Thompson BT, Ferguson ND, Caldwell E, et al. Acute respiratory distress syndrome: the Berlin Definition. JAMA. 2012;307:2526-33.

4. Torres-Aguilar O, Rodríguez-Prieto G, Castillejo-Suastegui H, Monares-Cepeda E, Aguirre-Sánchez J, Franco-Granillo J. Utilidad del ultrasonido de pulmón en la titulación de la PEEP en pacientes con síndrome de insuficiencia respiratoria aguda clasificación Berlín moderado y grave. Med Crit. 2017;31:7-15.

5. Guérin C, Reignier J, Richard JC, Beuret P, Gacouin A, Boulain T, et al. PROSEVA study group*. Prone positioning in severe acute respiratory distress syndrome. N Engl J Med. 2013;368:2159-68. 